\title{
Experimental DEM Extraction from ASTER Stereo Pairs and 3D Registration Based on ICESat Laser Altimetry Data in Upstream Area of Lambert Glacier, Antarctica
}

\author{
G. Hai ${ }^{\text {a, b }}$, H. Xie ${ }^{\text {a, b* }}$, J. Chen ${ }^{\text {a, b }}$ L. Chen ${ }^{\text {a, b }}$, R. Li $^{\text {a, b* }}$, X. Tong a, b \\ ${ }^{a}$ Center for Spatial Information Science and Sustainable Development, Tongji University, 1239 Siping Road, Shanghai, China - \\ (ganghai, huanxie, 1995jiajinchen, 103495chen, rli, xhtong)@ tongji.edu.cn \\ ${ }^{\mathrm{b}}$ College of Surveying and Geo-Informatics, Tongji University, 1239 Siping Road, Shanghai, China
}

\author{
Commission III, WG III/9
}

KEY WORDS: ASTER, Stereo Pairs, DEM, Registration, ICESat, Lambert Glacier, Antarctica

\begin{abstract}
:
DEM Extraction from ASTER stereo pairs and three-dimensional registration by reference to ICESat laser altimetry data are carried out in upstream area of Lambert Glacier, East Antarctica. Since the study area is located in inland of East Antarctica where few textures exist, registration between DEM and ICESat data is performed. Firstly, the ASTER DEM generation is based on rational function model (RFM) and the procedure includes: a) rational polynomial coefficient (RPC) computation from ASTER metadata, b) L1A image product de-noise and destriping, c) local histogram equalization and matching, d) artificial collection of tie points and bundle adjustment, and e) coarse-to-fine hierarchical matching of five levels and grid matching. The matching results are filtered semi-automatically. Hereafter, DEM is interpolated using spline method with ground points converted from matching points. Secondly, the generated ASTER DEM is registered to ICESat data in three-dimensional space after Least-squares rigid transformation using singular value decomposition (SVD). The process is stated as: a) correspondence selection of terrain feature points from ICESat and DEM profiles, b) rigid transformation of generated ASTER DEM using selected feature correspondences based on least squares technique. The registration shows a good result that the elevation difference between DEM and ICESat data is low with a mean value less than 2 meters and the standard deviation around 7 meters. This DEM is generated and specially registered in Antarctic typical region without obvious ground rock control points and serves as true terrain input for further radar altimetry simulation.
\end{abstract}

\section{INTRODUCITON}

The Advanced Spaceborne Thermal Emission and Reflection Radiometer (ASTER) on NASA's Terra spacecraft collects intrack stereo pairs using nadir and backward looking near infrared sensors. Since 2000, these stereo pairs have been used to produce single-scene $(60 \times 60 \mathrm{~km})$ digital elevation models with vertical accuracy (root-mean-squared-error) generally between $10 \mathrm{~m}$ and $25 \mathrm{~m}$ (Tachikawa et al., 2011). ASTER Global Digital Elevation Model (ASTER GDEM) is one of the biggest stereo data products in the world. As a whole, it lasts long in duration and has a large volume of data. However, ASTER GDEM has not been widely used in Antarctic ice sheet because the image data where ASTER GDEM derived from lacks strong texture and feature, especially in inland, and the DEM data includes many spikes, wells and gross elevation errors which significantly decrease the quality and elevation accuracy in local areas (Arefi et al., 2011).

Nevertheless, some studies imply the possibility that highquality ASTER DEM could be regenerated or improved in the area of Antarctic and mountain glaciers (Cook et al., 2012; Girod et al., 2015, 2016). A new 100-m Digital Elevation Model of the Antarctic Peninsula improved from ASTER Global DEM is presented with a mean elevation difference of $-4 \mathrm{~m}$ ( $\pm 25 \mathrm{~m}$ RMSE) from ICESat (compared to $-13 \mathrm{~m}$ mean and $\pm 97 \mathrm{~m}$ RMSE for the original ASTER GDEM), and a horizontal error of less than 2 pixels (between 106-161 m) (Cook et al., 2012). AST 14 (ASTER DEMs) are corrected together with ICESat laser altimetry observations to detect surface elevation changes over time, in which a general method of 3D similarity transformation is used (Schenk et al., 2016). For the study of mountain glacier mass balance, a tool is developed to compute RPC models from the ASTER metadata and a method which improves the quality of the matching by identifying and correcting jitter induced cross-track parallax errors. More accurate DEMs are generated with less unmatched areas and reduce overall noise (Girod et al., 2015, 2016). In the preliminary studies, the ASTER GDEM is improved but the resolution cannot meet the need of precise quantitative research and the regenerated ASTER DEM is produced only in a local experimental area, which limits a wide range of scientific application in vast Antarctica.

Therefore, in the typical inland region of Antarctica we have implemented an experiment of extracting reliable DEM from ASTER stereo pairs and registration on the basis of ICESat data in 3D space, which will support the further scientific study.

\section{STUDY AREA AND DATA SET}

\subsection{ASTER Image Data}

ASTER is a 15-channel imaging instrument operating on NASA's Earth Observing Terra morning orbital platform since 1999. One of the three separate optical subsystems of ASTER for stereo measuring is the visible and near infrared (VNIR) radiometer, acquiring images in 3 bands with a $15 \mathrm{~m}$ resolution. ASTER acquires images in all bands with a swath width of 60 
$\mathrm{km}$ (Abrams, 2016). 1-D searching in the along-track direction for image matching is sufficient to find the maximum correlation point if reconstructed unprocessed ASTER data (Level-1A data) is used as the source data for DEM products (Fujisada et al. 2011). In addition to acquiring a nadir-look in VNIR band 3, there is a backward-looking telescope operating in the same spectral range. A stereo pair is collected when there is a VNIR data acquisition. The backward-looking and nadir visible bands have a $27.60^{\circ}$ degree look angle, resulting a baseto-height ratio of 0.6. Standard stereo correlation was used to produce individual scene models at $30 \mathrm{~m}$ postings.

Our study area is located in upstream of Amery ice shelf with less rock coverage (Figure 1). The ASTER L1A image pair, which is acquired on 22nd, Jan, 2013, owns an overlapping area of 62 by $62 \mathrm{~km}$ in the ground. The images are high-quality with hardly any cloud cover and the sun azimuth and elevation are separately $124^{\circ}$ and $27.9^{\circ}$. The images are geo-coded relative to WGS84 ellipsoid through the auxiliary files.

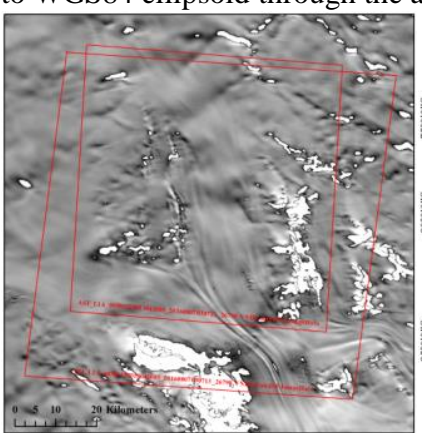

(a)

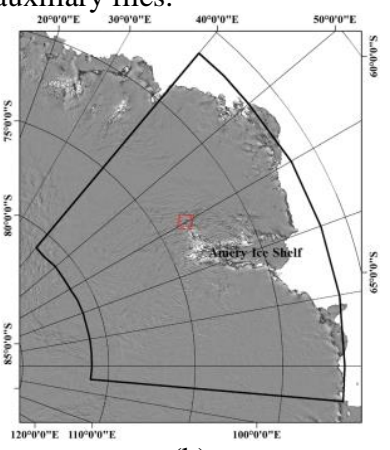

(b)
Figure 1. Study area and ASTER image coverage. (a) Two red boxes are ASTER L1A nadir and backward image boundary. Background image is MOA (Scambos et al., 2007). (b) Black sector polygon represents Lambert-Amery System. Red box shows the study area and corresponding image boundary.

\subsection{ICESat Laser Altimetry Data}

For DEM registration and validation, the newly released ICESat GLA12 dataset (R634) - Antarctic and Greenland ice sheet altimetry data is used. This dataset has been recently updated due to the error (the Gaussian-centroid or "G-C" offset) in the range determination from the transmit-pulse reference-point selection. Applying the range correction for the G-C offset improved the range precision by $1.7 \mathrm{~cm}$ to $<2 \mathrm{~cm}$, and mitigated ICBs (inter-campaign biases). ICBs have been reported to have a maximum impact on the elevation change of $\pm 10 \mathrm{~cm}$ per year (Borsa et al., 2014).

The ICESat laser altimetry data cover the entire mission period (Jan, 2003- Oct, 2009) with a compromised campaign strategy because of the failure of a part of sensor system (Shutz et al., 2005). For some inevitable reasons, the data from three campaigns (1, 17 and 18) was excluded from this study. Finally, 21,665 measurement points of ICESat falling within study area are split into mainly 9 feasible tracks with 5 of ascending and 4 of descending.

\section{METHODOLOGY}

Implementation of DEM extraction using ASTER stereo pairs and the following registration by reference to ICESat data in three-dimensional space will be introduced (Figure 2). Meanwhile, the key intermediate process will be presented. All the main procedure could be found by reading the flowchart (Figure 2).

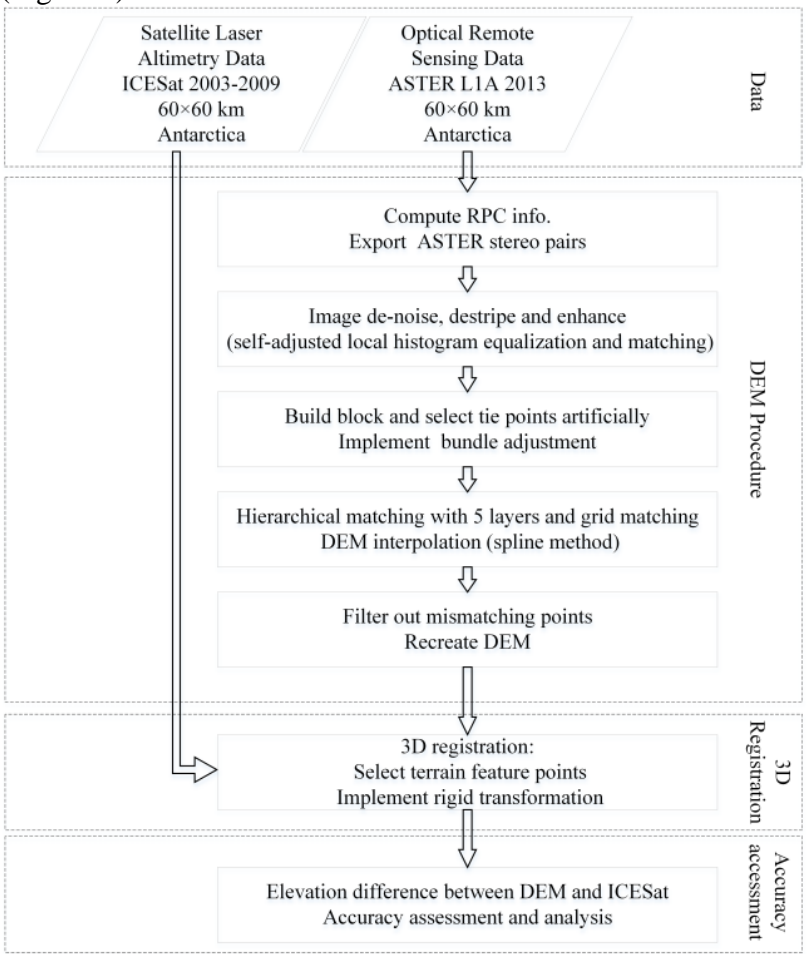

Figure 2. Flowchart of DEM Extraction and 3D Registration.

\subsection{DEM Extraction}

ASTER L1A HDF file is used as input data for the whole DEM extraction workflow, which is based on Rational Function Model (RFM). After extracting the images and metadata, we start by estimating Rational Polynomial Coefficient (RPC) for both stereo images (Band 3N and 3B) using the ENVI 5.3. Then we remove noise using Warris operator. Each ASTER image is implemented with a further calibration of the striping (Girod et al., 2015). For preparation of image matching, histogram equalization is specially performed. Before bundle adjustment, over 400 pair of correspondences are artificially selected for lack of strong texture in most part of the images and accurate ground control points (GCPs) are not available because rock feature is less.

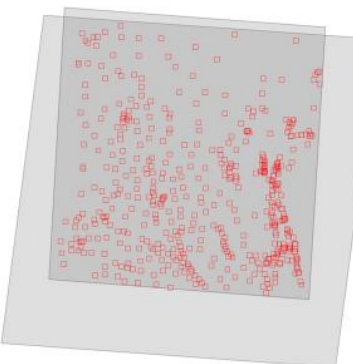

(a)

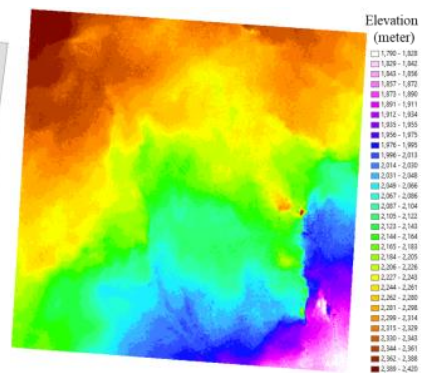

(b)
Figure 3. Distribution of tie points and produced DEM. (a) Over 400 manual tie points (red box) with high accuracy are selected with uniform distribution. (b) The produced ASTER DEM displayed here is implemented with registration. The DEM is in the Antarctic Polar Stereographic projection with a true-scale at $71^{\circ} \mathrm{S}$ based on the WGS 84 ellipsoid datum.

The DEM extraction procedure was carried out by using the ERDARS 2014 Leica Photogrammetric Suite (LPS). The enhanced Automatic Terrain Extraction (eATE) module is used 
for DEM (digital elevation model) derivation, which performs a coarse-to-fine hierarchical matching process with 5 layers (Li et al., 2017). The NCC (normalized correlation coefficient) matching window is set as 11 by 11 pixels with search window of 25 by 25 pixels, and the top layer correlation coefficient threshold was set as 0.9 to ensure the accuracy of matching propagation of down-layers. Along with hierarchical matching, Least Squares refinement is implemented at the fifth layer to avoid or mitigate pixel-locking. (Leica Geosystems, 2006). After removal of outliers, the produced DEM is interpolated having a grid spacing of $30 \mathrm{~m}$ (Figure 3 ).

\subsection{D Registration}

Because of lacking GCPs, the generated DEM is not controlled well in absolute ground coordinate system. By comparing with the ICESat laser altimetry data, which is accurate enough with the absolute elevation error less than $15 \mathrm{~cm}$ (Shuman et al., 2006), slight rotation and translation between the ASTER DEM and the ICESat data exist in 3D space. The scale factor is regarded as rather small magnitude which could be neglected.

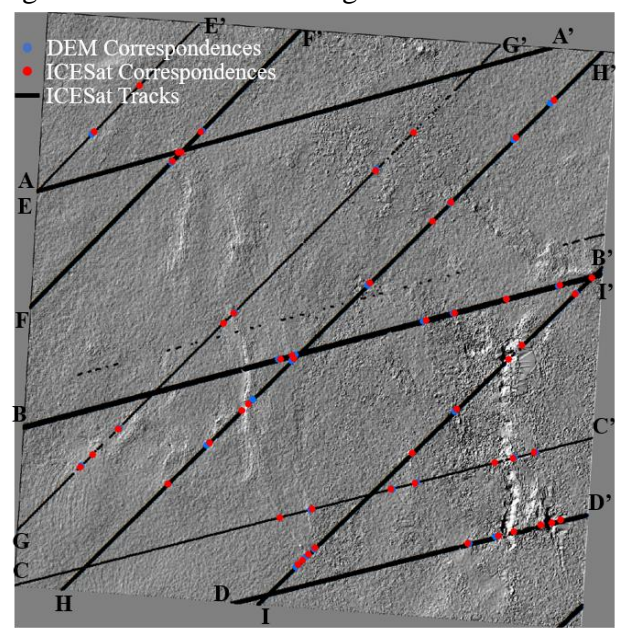

(a)

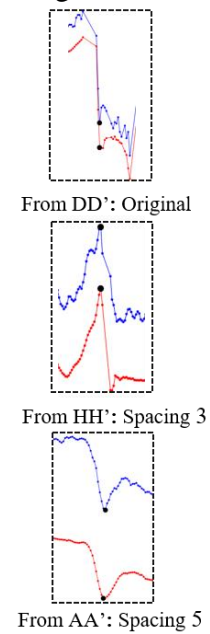

(b)
Figure 4. ICESat tracks and selected correspondences. (a) The background image is a shaded relief map derived from the ASTER DEM with sun azimuth of $124^{\circ}$ and sun elevation of $27.9^{\circ}$. Blue and red points are correspondences selected from ICESat and DEM profiles. (b) Three strategies of correspondence selection for different terrain features.

Before compensating for rotation and translation, we select terrain feature points separately from ICESat profiles and corresponding DEM profiles semi-automatically at present. Control terrain features include abrupt slope changes and ridge crests. 52 correspondences from profiles are determined using a smoothing strategy. For track across hill with large elevation gradient, correspondences are selected from ICESat profile and original DEM profile. For track across mega dune with medium elevation gradient, correspondences are selected from ICESat profile and smoothed DEM profile by 3 points. For track across dune with small elevation gradient, correspondences are selected from ICESat profile and smoothed DEM profile by 5 points (Figure 4).

Then Least-squares rigid transformation is conducted using SVD after selection of correspondences (Sorkine-Hornung et al., 2017). First, both DEM points and ICESat points are centralized. Second, selected correspondences are used for estimating rigid transformation. As expected, the rotation angle decomposing from rotation matrix is very small. The estimated translation parameters for $\mathrm{X}, \mathrm{Y}$ and $\mathrm{Z}$ directions are about 28. 3, 27.9 and -40.8 meters, which is acceptable. As a whole, the ASTER DEM is shifted towards northeast direction and downwards. Figure 5 shows the 3D perspective of the final DEM.

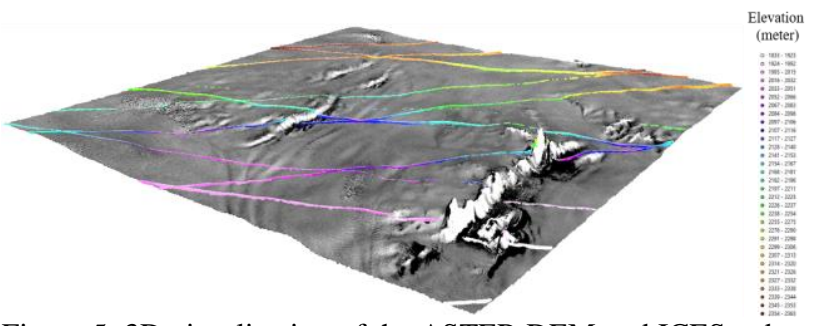

Figure 5. 3D visualization of the ASTER DEM and ICESat data. The nadir image of ASTER band 3 is overlaid on the ASTER DEM. It is mapped based on the WGS 84 ellipsoid datum. The factor of vertical exaggeration is 10 .

\section{RESULTS AND ANALYSIS}

\subsection{ASTER DEM Validation}

The ASTER DEM is extracted and thus registrated reference to ICESat data. All the existed ICESat points $(21,665)$ are used to make comparison between the ASTER DEM and ICESat data. After 3D registration, the elevation difference between them decrease to mean value of -1.93 meters and standard deviation of 7.03 meters (Figure 6).

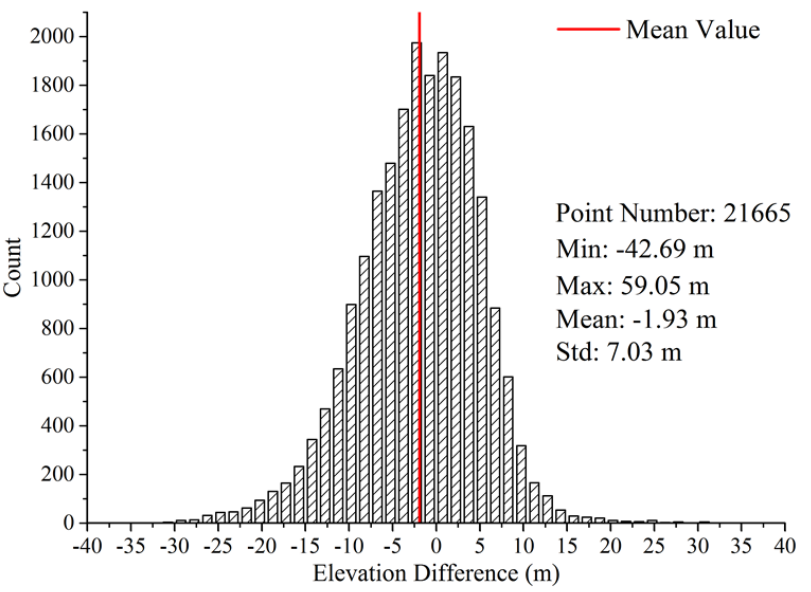

Figure 6. Histogram of the elevation differences between points from the ASTER DEM and ICESat profiles.

\subsection{Analysis of Profiles}

Terrain feature for this study area could be summarized as three main types: dune, mega dune and hill. Therefore, three profiles for the corresponding terrain are plotted here to demonstrate how good the result is. There is a good agreement between profiles of the ASTER DEM and ICESat data (Figure 7).

According to the above profiles, we discover that the DEM produced from ASTER stereo pairs hold the potential in distinguishing small dunes even with height less than 20 meters, which is significant for prior terrain input of radar altimetry echo simulation (Figure 7 (a) and (b)).

In the study area, we made a statistic of 9 strip of curved terrain features including 3 dunes, 5 mega dunes and 1 hill at aspects of measuring their length, width and height. These dunes and hill 
play an important role in affecting the echo waveform of radar altimetry. The basic discipline we found is that there is linear positive correlation among the length, width and height of these curved terrain features.

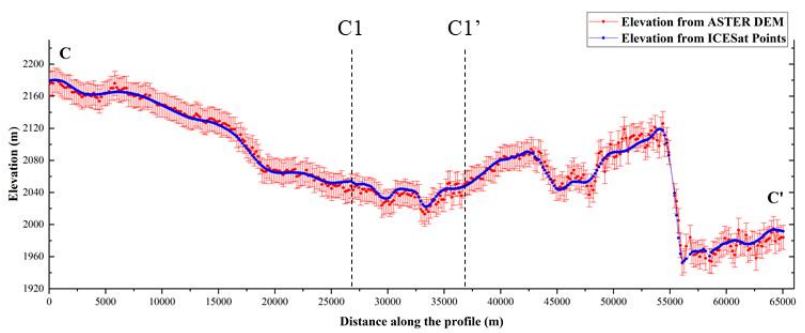

(a)

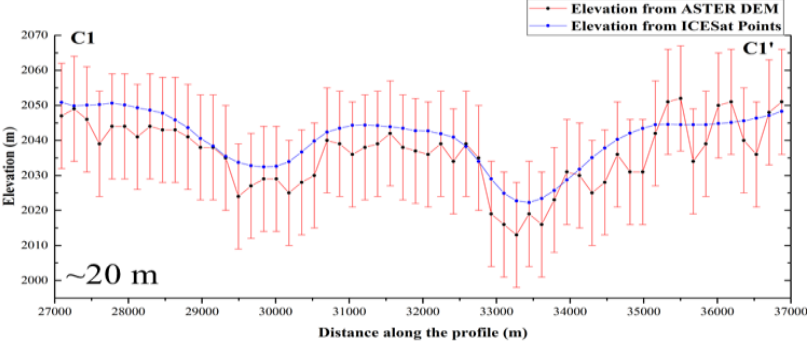

(b)

Figure 7. An example of comparison between ASTER DEM and ICESat profiles. (a) Terrain type: hill. (b) Partial details between point $\mathrm{C} 1$ and $\mathrm{Cl}$ ' come from profile $\mathrm{CC}$ '. Both of the two error bars are 15 meters.

\section{CONCLUSION AND FUTURE WORK}

We explored a complete and reliable workflow of DEM generation from ASTER L1A stereo pairs and 3D registration by reference to accurate satellite laser altimetry data of ICESat in Antarctica typical region where strong image textures are insufficient. The ultimate produced DEM is proved to be at an acceptable accuracy in spite of lacking GCPs. Meanwhile, we found that snow dunes over 15 meters could be discriminated from the ASTER DEM. This will be of great help for our future radar altimetry echo simulation.

Additionally, it is possible that the accuracy of the ASTER DEM can be further improved. In process of the registration, only along-track location information is considered at present, which will limit the accuracy of the registration result because the information towards other directions especially across-track direction is not taken into account. In our future work, this will be improved through more rigorous correspondence selection strategy.

\section{ACKNOWLEDGEMENTS}

This work has been supported by National Key Basic Research Program of China (Project No. 2012CB957701) and the National Natural Science Foundation of China (Project No. 41571407). We acknowledge the support from Zhen Ye, Yi Lv, Haifeng Xiao, Guanjie Tang, Yixiang Tian and Shijie Liu from Tongji University. We would like to thank USGS and NSIDC data centre for providing ASTER and ICESat data.

\section{REFERENCES}

Abrams, M., 2016. ASTER Global DEM Version 3, and new ASTER Water Body Dataset. ISPRS-International Archives of the Photogrammetry, Remote Sensing and Spatial Information Sciences, 107-110.

Arefi, H., and Reinartz, P., 2011. Accuracy enhancement of ASTER global digital elevation models using ICESat data. Remote Sensing, 3(7), 1323-1343.

Borsa, A. A., Moholdt, G., Fricker, H. A., and Brunt, K. M. 2014. A range correction for ICESat and its potential impact on ice-sheet mass balance studies. The Cryosphere Discuss, 7, 4287-4319.

Cook, A. J., Murray, T., Luckman, A., Vaughan, D. E., and Barrand, N. E., 2012. A new 100-m Digital Elevation Model of the Antarctic Peninsula derived from ASTER Global DEM: methods and accuracy assessment. Earth System Science Data, 4(1), 129-142.

Fujisada, H., Urai, M., and Iwasaki, A., 2011. Advanced methodology for ASTER DEM generation. IEEE Transactions on Geoscience and Remote Sensing, 49(12), 5080-5091.

Girod, L., Nuth, C., and Kääb, A., 2015. Improvement of DEM Generation from Aster Images Using Satellite Jitter Estimation and Open Source Implementation. The International Archives of Photogrammetry, Remote Sensing and Spatial Information Sciences, 40(1), 249.

Girod, L., Nuth, C., and Kääb, A., 2016. GLACIER VOLUME CHANGE ESTIMATION USING TIME SERIES OF IMPROVED ASTER DEMS. International Archives of the Photogrammetry, Remote Sensing \& Spatial Information Sciences, 41.

Li, R., Ye, W., Qiao, G., Tong, X., Liu, S., Kong, F., and Ma, X., 2017. A New Analytical Method for Estimating Antarctic Ice Flow in the 1960s From Historical Optical Satellite Imagery. IEEE Transactions on Geoscience and Remote Sensing, 55(5), 2771-2785

Scambos, T. A., Haran, T. M., Fahnestock, M. A., Painter, T. H., and Bohlander, J., 2007. MODIS-based Mosaic of Antarctica (MOA) data sets: Continent-wide surface morphology and snow grain size. Remote Sensing of Environment, 111(2), 242-257.

Schenk, T., Csatho, B. M., and Duncan, K., 2016. FUSION OF LASER ALTIMETRY DATA WITH DEMS DERIVED FROM STEREO IMAGING SYSTEMS. ISPRS-International Archives of the Photogrammetry, Remote Sensing and Spatial Information Sciences, XLI-B8(31-536).

Schutz, B. E., Zwally, H. J., Shuman, C. A., Hancock, D., and DiMarzio, J. P., 2005. Overview of the ICESat mission. Geophysical Research Letters, 32(21).

Shuman, C. A., Zwally, H. J., Schutz, B. E., Brenner, A. C., DiMarzio, J. P., Suchdeo, V. P., and Fricker, H. A., 2006. ICESat Antarctic elevation data: Preliminary precision and accuracy assessment. Geophysical Research Letters, 33(7).

Sorkine-Hornung, O., Rabinovich M., 2017. Least-Squares Rigid Motion Using SVD. Technical Notes. Department of Computer Science, ETH Zurich, Switzerland. 